\title{
Two Modes of Investment Banking: Technocrats, Relationship Managers, and Conflict
}

by Alan D. Morrison and William J. Wilhelm, Jr., University of Oxford and University of Virginia

n the last decade, a number of firms that we used to call "investment banks" have
succumbed to conflicts of interest. The LIBOR scandal uncovered evidence that

some institutions had systematically undermined their clients' interests by manipulating standard interest rate fixes in pursuit of trading profits. Organized rigging of standard currency market settlement rates led to substantial fines for the firms concerned. Several banks were accused in the wake of the 2008-09 financial crisis of selling complex securitizations to unsophisticated clients who might have expected their advisors to steer them away from such trades. A series of cases in the Chancery Court of Delaware provide strong prima facie evidence that some sell-side M\&A bankers placed their own interests before their clients' by steering deals to favored bidders that may not have been willing to pay the highest price to acquire the client's firm.

What's more, the UK's Financial Conduct Authority has uncovered evidence that some banks allocate shares in initial public offerings (IPOs) so as to benefit their buyside clients at the expense of the issuing companies. ${ }^{1}$ The 2013 settlement of a lawsuit related to eToy's 1999 IPO indicated that Goldman Sachs went further by demanding kickbacks from buy-side clients in the form of commission business. One does not have to search hard for other, similar cases. Goldman Sachs features in many of the cases we examine. That is not because we wish to argue that Goldman is any more culpable in the problems we address than any other bank. Indeed, we think one can make the case that Goldman is a particularly introspective and thoughtful institution. If it is hard for Goldman to navigate the

1 Tim Jenkinson, Howard Jones, and Felix Suntheim provide evidence that brokerage revenues were a significant determinant of investors' IPO allocations and profits in a sample of 220 IPOs conducted from the U.K. between January 2010 and May 2015. See "Quid Pro Quo? What Factors Influence IPO Allocations to Investors?," Journal of Finance, October 2018. complex investment banking landscape, then it is hard for anyone to do so.

Are these examples evidence of an insidious problem in financial markets? And, if they are, what is their root cause? Our answer to these questions builds on a theory of investment banking that we outlined in a 2007 article in this journal. ${ }^{2}$ That article identified traditional investment banking as a relational activity. That characterization, and its interpretation, reflect the historic role of investment banks. Since they first emerged in the 19th century, investment banks have always worked on complex and hard-to-document transactions whose parties cannot agree on terms unless they truthfully share information.

For example, an initial public offering requires an exchange of information between the issuing firm and potential investors, but each side has an incentive to protect the

2 A.D. Morrison, and W.J. Wilhelm, Jr., "Investment Banking: Past, Present, and Future," Journal of Applied Corporate Finance Studies, Winter 2007. 
strategic advantage that it derives from its private information. Moreover, it is impossible to contract upon this sort of information; only a trusted intermediary can persuade the counterparties to reveal their information. Investment banks sustain that trust by building close counterparty relationships in order to maintain a reputation for fair dealing. The traditional ownership and governance structures of investment banks encouraged effective reputation management, thereby cementing the trust upon which relational banking relies.

This argument has an important corollary. The parties to a relational business have divergent interests and their actions are, at best, only partially contractible. Each party therefore relies upon the relational bank to represent its interests fairly. This means that relational investment bankers inevitably face conflicts of interest. Conflict is inevitable in investment banks because they cannot contract upon the information exchange that underpins relational banking; we make the stronger claim that it is actually a deliberate and important feature of the organizational design. That is, we argue that relational bankers exist to assume and to manage conflicts of interest that would otherwise prevent valuable economic activity from occurring. When the Morgan Stanley banker Robert Kindler stated that "we are totally conflicted," he was therefore expressing both a truism and a raison d'être. ${ }^{3}$ But it is important that we can trust relational bankers to manage their conflicts appropriately for, if they do not, we will fail to realize all of the benefits capitalism is capable of providing. We therefore question the apparent lack of concern with which Mr. Kindler went on to recommend that we "get used to" conflicts in banking.

Today's banks combine their traditional relational activities with what might be described as a new, technocratic, kind of banking. Technocratic bankers specialize in finding formal and codified ways of doing business in financial markets. A rules-based auction that sells a firm's new share issue without leaving the organizing banker any scope to exercise judgment is a technocratic product; so, too, is an interest rate swap that lays down in black and white each party's obligations as well as their rights to break the contract. Technocratic banking requires a form of skill that emerged for the first time after 1970, as bankers came to appreciate the opportunities afforded by the intelligent use of computers and the new discipline of financial engineering.

Technocratic and relational banking are uneasy bedfellows, because they tend to be associated with different cultural values. Relational banking is concerned always and everywhere with the management of conflicts; relational banking culture

3 See Andrew Ross Sorkin, "When a Bank Works Both Sides," New York Times, April 8, 2007. therefore values the ability to resolve difficult conflicts in such a way as to maintain the bank's reputation and the trust upon which future relational business rests. In contrast, technocratic banking relies much less on the exercise of judgment: technocratic bankers use tailored contracts to deal with conflicts of interest, and, accordingly, their culture values the ability to design such contracts over the ability to exercise judgment, maintain trust, or manage institutional reputation.

These observations make for a serious governance problem in large financial institutions that combine relational and technocratic banking. On the one hand, relational bankers emphasize the protection of the firm's reputation and the exercise of appropriate judgment in the face of conflicts. If such a banker has to decide between showcasing an ability to structure a difficult deal and looking after his client in a less showy way, he may take the latter course. On the other hand, technocratic bankers are less concerned with the firm's reputational assets and so are more willing to risk depleting their value when doing so helps them to build the sort of personal and technical reputation that is most valuable in their business. That is, concern for personal reputation and the desire to build a star profile may lead a technocratic banker to behave in ways that harm the firm's reputation for fair dealing and, in so doing, to undermine the firm's relational business. The full-service bank has cultural conflicts wired into its DNA; if it proves unable to govern its workers, those conflicts will undermine one or both of its businesses.

A natural response to this problem might be simply to separate relational from technocratic activities by placing them in different firms. This is the rationale for the boutique advisory banking firm, which started to emerge around 1990 as a "conflict-free" response to the problems created when relational and technocratic businesses are combined. ${ }^{4}$ But this is a costly solution. Relational and technocratic banking are increasingly braided. That is, they are deliberately combined because each can benefit from the presence of the other. A relational banker may be able to use technocratic products to encourage trust in extra-legal trade, while a technocratic banker may be able to sell new products as part of a complex and extra-legal agreement brokered by relational bankers.

In principle, such braiding of relational and technocratic services can occur at arm's length: sell-side M\&A clients sometimes hire a boutique advisory firm to work alongside or to monitor a full-service bank with stronger technocratic capabilities. However, aside from the costly duplication of

4 Wasserstein Parella was founded in 1988 when Joseph Parella and Bruce Wasserstein walked away from First Boston indicating that they were unhappy with the direction of the bank (Financial Times, 1/24/16). Other early advisory boutiques include Gleacher Partners (1990), Evercore (1995), and Greenhill \& Company (1996). 
effort that results from this approach, braiding may enable a full-service bank to benefit from scope economies and common governance arrangements. If so, it follows that we cannot completely avoid the complicated governance and conflict-management problems that arise in full-service banks, and that we must therefore manage those problems.

But it is hard to do so, because the functional braiding that conjoins relational and technocratic approaches to banking has yet to produce cultural standards that bridge the two ways of doing business. Tim Leissner, the Goldman Sachs banker at the heart of the scandal surrounding embezzlement and fraud at the Malaysian state investment fund 1MDB, claimed that it was "very much in line" with Goldman's culture to conceal things from the bank's compliance department. His claim is consistent with the statement that he was selling a technocratic service. ${ }^{5}$ But what it also indicates is that, despite nearly a decade of serious attempts to do so, the firm has yet to find a way to reconcile the cultural differences that are woven into its braided business model.

In short, we paint a picture of an industry suffering from a crisis of trust. We contend that this is one of the most serious problems facing our financial system and, by extension, the capitalist system that relies upon it. The crisis is structural: it dates back to the emergence of technocratic banking and it has gathered pace as technocratic and relational banking have become increasingly braided in the most important financial firms. Attempts to address the problem through the medium of corporate values statements have so far proved ineffective; so, too, have attempts to regulate corporate behavior in the wake of the financial crisis.

We can therefore reasonably claim to address hugely important problems. We do not present simple solutions; instead, we present a careful outline of the theory that underpins our analysis, and we bring it to bear on several recent transactions. We conclude by asking how our analysis might inform thinking within banks and their regulators, and we discuss some of the ways in which technology might start to create governance solutions as well as cultural problems in the investment-banking sector.

\section{Relational Investment Banking}

\section{Information Sharing and Investment Banking}

Our 2007 article began by asking why modern economies need investment banks. ${ }^{6}$ Our answer started from the observa-

5 See David Crow and Laura Noonan, "Tim Leissner: Goldman Sachs banker at the heart of 1MDB scandal," Financial Times, December 23, 2018.

6 The theory was presented in detail in our book: See A. D. Morrison and W. J. Wilhelm, Jr. (2007) Investment Banking: Institutions, Politics, and Law, Oxford: Oxford University Press. tion that large-scale financial trades are often difficult because the information needed to assess them and assign prices to the relevant securities is widely dispersed.

Consider, for example, the setting for an initial public offering of equity, or IPO. Insiders of the issuing firm are privy to information about its business prospects that may be difficult to reveal even under a strong regulatory disclosure regime. On the other hand, institutional investors have specialist knowledge about market conditions. Unless both issuer and investors can credibly share their information, the offering cannot be accurately priced and could even fail. If we are to realize the social advantages that derive from an efficient capital market, the parties to the securities transaction must therefore be induced to exchange their information and to have it certified for accuracy.

Market exchange in most goods is relatively straightforward. But it is hard to prove that information has been exchanged, and it is even more difficult to prevent multiple sales of the same information. As a result, there are no standard textbook markets for information. Investment banking is a response to this problem: investment bankers design deal structures and informal agreements that provide their counterparties with incentives to share information in the absence of any legal obligations to do so. That is, investment bankers create extra-legal markets for information. For example, in addition to securities offerings, investment banks mediate the production, packaging, and resale of information in M\&A, or, more generally, the market for corporate control.

In creating what amounts to a forum for informational exchange, the two most important weapons at the disposal of an IPO banker are, first, the credibility required to be able to certify the issuer's representations; and, second, the ability to influence the offer price and share allocations. Several studies have shown that the use of more reputable banks improves the terms of trade for issuers, and that bankers reward information production by institutional investors by allocating shares at a discount to their fair price. The latter practice, which is a critical part of the book-building process, works when information production is performed by institutions that deal repeatedly with the bank; the threat that the bank will cease to allocate them cheap shares in the future then keeps them from lowballing their bids, or cherry-picking the best deals today.

It is worth emphasizing once again that the process outlined above is extra-legal, and so lies completely beyond the reach of formal contract. The bank's reputation supplements formal regulatory disclosure requirements. The investment banker's promise of underpriced shares in exchange for information cannot be contractual, because information exchange is not contractible. Similarly, the punishment triggered by a 
failure to perform is not contractual, because it is impossible to prove a failure to produce accurate information. The bank's formal rights to price and to allocate shares underpin the carrots and sticks needed to generate information exchange, but no contract can force the bank to use these rights as we have described them.

The IPO process that we have outlined rests upon two important pillars. First, the parties to an IPO must have a common understanding of the rules by which the IPO game is to be played; that understanding includes an appreciation of the fact that those rules are extra-legal and incomplete, so that they must be supplemented by good judgment. Second, everyone involved must trust the bank to play by the commonly understood rules of the game, and to exercise judgment appropriately when it is necessary.

Initial public offerings thus rely upon rules that are fashioned in a community of market participants, and upon judgment that is evaluated by the same community. The investment bank must acquire a deep understanding of its community, because the bank exercises judgment in the shadow of its community's expectations; in exercising judgment, it establishes precedent and so exercises leadership over its community. The investment bankers who fulfil this role must therefore supplement their knowledge of finance with an ability to build and to manage the complex web of relationships within which they operate. Their activity is fundamentally relational.

\section{Relational Banking and Conflicts of Interest}

Relational bankers are embedded within, and provide leadership to, communities of practice that together form a common understanding of the ways in which their community should operate. By "practice," we mean a financial activity like selling new securities, selling control over a firm's assets, or helping an investor to build a balanced portfolio. The community that engages in a banking practice has a common interest in the continued success of the practice, but its members typically do not have common aims when they engage in the practice.

For example, the participants in an IPO have a common long-run desire for a well-functioning IPO market, but they have divergent goals when they participate in a specific stock offering. The owners of the issuing firm want to sell its shares at the highest possible price, while the share buyers want to acquire them as cheaply as possible. Each has an immediate interest in misleading the other, and the investment bank operates the IPO according to commonly understood rules in such a way as to ensure that information is shared and the shares are priced correctly. The parties to the IPO will assess their banker's actions and will decide whether they were appropriate; but if they cannot codify the rules they have no choice during the IPO but to trust their banker to know what rules are relevant and then to follow them.

This argument is equally true of most M\&A advisory work. For example, a sell-side bank that accepts a fee for selling a client's business manages the flow of information between the seller and potential bidders by advising the seller on which firms to invite to participate and how information should be disseminated at each stage of the bidding process. Each bidder would prefer to be one of a small pool of potential buyers, but an excessively small pool would likely lower the selling price and so harm the client. Moreover, it is likely that the sell-side banker will have relationships with some potential buyers, especially financial buyers, and thus be in a better position to judge their capabilities and bidding behavior. The sell-side investment bank therefore faces a conflict between the interests of its contractual client and potential bidders, some of whom it may deal with more frequently in either a buy-side or sell-side capacity. In such cases, the investment bank's client is forced to rely upon the investment bank's reputation for making the necessary trade-offs in the right way.

This type of banking is difficult and it relies heavily upon the banker's experience and judgment. It is essential precisely because the banker's counterparties have conflicting interests. We believe that this is a critical point, and that it is frequently overlooked in discussions of investment banking. The relational investment banker exists in situations where, first, formal contracting, and even precise negotiation, are impossible; and, second, where the parties to a transaction are conflicted. The banker often cannot be held to account for failures to manage that conflict appropriately; and, hence, from a purely legalistic perspective, it is able to abuse its position. Indeed, if legal devices were sufficient to keep the investment banker in line, then its actions would be contractible, and the banker would be redundant; when investment bankers are needed, they are themselves conflicted, and they are viable to the extent that their counterparties trust them to manage their conflicts. We have therefore arrived at a deeper explanation of investment banking: The relational investment banker's role is to assume and to manage conflicts of interest in informationally sensitive financial transactions.

\section{The Institutional and Cultural Basis of \\ Relational Investment Banking}

The relational banker cannot operate without the trust of his community of practice. That trust exists at two levels. Most obviously, the banker's clients must believe that he will treat them fairly and that he will never respond inappropriately to 
the conflicts that he faces. That trust is founded upon the way in which his character is perceived-that is, upon his character reputation.

Relational bankers assemble teams to meet their clients' needs. The composition of those teams, and the demands placed upon them, are hard-to-know ex ante, and they are almost impossible to appraise after the fact, at least to the level required for formal legal adjudication. The banker therefore relies upon the character of his peers, and upon the perception that his clients have of that character. In other words, the relational banker understands that he needs his firm to be trusted to supply people whose decisions will reflect the right character traits. This trust is founded upon a firm-level reputation, which we refer to as the firm's relational reputation.

We claim that, while a personal character reputation is a very valuable asset, it is of less importance to relational banking than a strong corporate relational reputation. The reason is that the (relatively) anonymous bankers provided by a firm with a strong relational reputation are trusted, by virtue of their firm's reputation, to exercise judgment appropriately. Individual bankers can therefore "borrow" their employer's reputation. When they do so, they have a chance to build a strong personal character reputation and, hence, their incentives and those of their firm are strongly aligned.

We identify two consequences of our discussion of character and relational reputations.

First, relational bankers naturally build institutional structures that support the development and the maintenance of relational reputation. Our previous work argues that this was the purpose of the traditional investment banking partnership. It was not uncommon in the first seven decades of the twentieth century for investment bankers to retain partnership stakes in their firms for several decades and, hence, their own fortunes were closely tied to the relational reputations of their employers. They protected those reputations by playing by the tacit rules of securities underwriting and M\&A advising, and by mentoring junior employees in order to pass on the skillsets that would protect the firm's standing.

The second effect of a reliance upon relational reputation was upon the cultural norms to which relational bankers subscribe. In making this point, we are forced by space considerations to elide a substantial literature on culture. ${ }^{7}$ For our purposes, culture comprises a common set of understandings and taken-for-granted normative assessments. Cultures

7 For recent surveys of this literature, see Orlando Patterson, Making sense of culture, Annual Review of Sociology, July 2014; and Simona Giorgi, Christi Lockwood, and Mary Ann Glynn, The many faces of culture: Making sense of 30 years of research on culture in organization studies, Academy of Management Annals, January 2015. emerge as social groups find ways to solve common problems, and they are embedded in the formal and informal procedures that those social groups use to organize themselves. In learning an organizational culture, then, one learns values and ways of behaving that enable one to participate in collective solutions to the organization's problems; one need not necessarily know every part of the solution and, moreover, no one need do so. ${ }^{8}$

The problems that gave rise to relational investment banking culture were solved through the creation of individual character reputations and institutional relational reputations. Cultural values in relational banking reflect the importance of those reputations. Relational bankers who place their clients first, who always give good advice even at some immediate personal cost, and who emphasize the strength and the survival of their institution are lauded and promoted. Relational bankers take these values for granted: they are embedded in the procedures and the stories that junior relational bankers learn at the feet of their senior colleagues. Only relatively recently did bankers make any attempt to reflect upon, and to codify, their values in formal statements.

\section{Technocratic investment banking Information Technology and the \\ Emergence of the Technocratic Banker}

The modern investment bank continues to engage in relational businesses that rely upon judgment and collective rule making. But its activities are supplemented by a new and more formal ways of doing business that we will refer to as technocratic banking. Technocratic banking emerged when Wall Street embraced new skills related to computing and financial engineering. We start this section by tracing the emergence of those skills.

Our earlier work catalogues the history of computation on Wall Street, from the early adoption of mainframe computing for overnight deal processing, via distributed realtime computations performed by desktop computers, to the modern technological landscape. The most obvious effect of computerization was that it enabled bankers to perform familiar calculations more quickly, but it had a much deeper

8 See Ann Swider, Culture in action: Symbols and strategies, American Sociological Review, April 1986; David M. Kreps (1990) Corporate culture and economic theory, in James E. Alt, and Kenneth A. Shepsle, ed.: Perspectives on Positive Political Economy, Cambridge, UK: Cambridge University Press; Steven Pinker (1997) How the mind works, New York: W.W. Norton \& Co; Edwin Hutchins (1995) Cognition in the Wild, Cambridge, Mass: MIT Press. A related point is made by Hayek, who argues that market societies rely upon complex, undersigned rules that no one fully understands: see F.A. Hayek (1990 [1973]) Law, Legislation and Liberty. Vol. 1: Rules and Order, Chicago: Chicago University Press. 
societal effect. That effect derived from the emergence of new markets and, with them, new types of skill. For example, the first spreadsheet programs were written to automate the discounted cash flow calculations that investment bankers learned on the blackboards of their business schools. Bankers learned how to use spreadsheets to analyze deals rapidly, and their new skills were used to refine spreadsheet design. The ability rapidly to manipulate vast quantities of accounting and other data was the basis of a new type of advisory banking; ultimately, this type of banking was used to create the first specialized markets in M\&A advice. ${ }^{9}$

By the 1980s, when investment bankers had access to fast desktop computers, they could use them to test and to refine the new mathematics of financial derivatives, which started to emerge after the 1973 publication of the Black and Scholes model. ${ }^{10}$ Computing and mathematics together ushered in the new investment banking skill of financial engineering. Financial engineers used formal models, new derivatives markets, and an associated new legal technology to create novel contracts that allowed market participants to parcel up and to exchange risks that had previously been untradeable. ${ }^{11}$

Their skills did far more than simply enable new forms of speculation. First, they allowed investment bankers and their clients formally to contract on events that, in the past, could cause economic transfers only as a result of indirect, trust-based, agreements. Second, they gave relational bankers new ways to induce their counterparties to cooperate in extralegal exchange: for example, it might be easier to induce an issuing firm's managers to exchange information if their firm issued a warrant bond. Such bonds are worth more if the firm can credibly reveal good information and, if it does not, they are treated as low-quality by the market, so that warrant bond issuers have strong incentives to find a way credibly to reveal good news if it exists. Hence, while informal strategies

9 For example, both Goldman Sachs and Morgan Stanley had very small, dedicated M\&A departments by the mid-1970s. Morgan Stanley's, started in 1974 by Robert Greenhill, used a Digital Equipment PDP-11 minicomputer for spreadsheet modeling. In contrast, Lazard's longstanding M\&A operation still used hand-held calculators for M\&A analysis in 1979. Source: Philip Keevil in private conversation and email, September 6 , 2017 and January 12, 2018.

10 F. Black and M. Scholes, "The Pricing of Options and Corporate Liabilities." Journal of Political Economy, 1973.

11 While this technology had to be recognized by the courts and by other state organs, it emerged organically from the practice of bankers and their transactions lawyers. A notable example is the ISDA Master Agreement. The International Swaps and Derivatives Association (originally the International Swaps Dealers Association) was established in the 1980s and negotiated standard-form contracts between the major derivatives traders that were published in Master Agreements in 1987, 1992, and 2002. The Agreement generated confidence in new derivatives contracts and, to some extent, insulated the nascent swaps markets from direct regulation. See John Biggins and Colin Scott, Public-Private Relations in a Transnational Private Regulatory Regime: ISDA, the State and OTC Derivatives Market Reform, European Business Organization Law Review, September 2012. remained important tools for relational bankers, they were supplemented by new formal contractual approaches.

The invention of financial engineering thus inspired investment banks to find new ways to achieve their clients' goals. The new approaches emphasized market solutions and formal contracts and, inevitably, some clients adopted the new approaches. Market-based activity therefore accounted for an increasing proportion of investment bank revenue while, at the same time, advisory businesses became correspondingly less important. For example, in 1998, the year before Goldman Sachs went public, investment banking accounted for $40 \%$ of the firm's total revenue. By 2007, investment banking's contribution had fallen to $25 \%$ of total revenue and did not rise above $23 \%$ over the next ten years. ${ }^{12}$ Technocratic risk-taking functions, both proprietary and on behalf of clients, largely accounted for the difference.

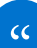

The relational investment banker's role is to assume and to manage conflicts of interest in informationally sensitive financial transactions... The technocratic banker's skillset is in structuring formal legal solutions to client problems.

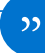

In short, new technologies enabled new forms of human capital and new markets in investment banking. Bankers endowed with the new human capital refined the markets in which they operated, and operating in those markets served, in turn, to refine the human capital of investment bankers. A cadre of professionals thus emerged whose source of wealth, and whose outlook on investment banking, was contractual and technocratic.

\section{Institutional and Cultural Basis of Technocratic Banking}

The technocratic banker's skillset is in structuring formal legal solutions to client problems. She does not need a reputation for playing by the rules of the game, because she can write those rules into a contract and commit herself legally to obey them. In other words, technocratic banking has a much smaller reliance upon relational reputation than does traditional relational banking. Technocratic bankers receive business because they have the right skills to process it, and their contractual commitments are credible to the extent that

12 Goldman Sachs, Annual Reports 
they have sufficient financial capital. Faced with a choice between financial scale and relational reputation, one would expect the technocratic bank to opt for financial scale.

This trade-off played out through the 1970s, 80s and 90s, as the major investment banks jettisoned the partnership form and went public. In doing so, they severed the close bonds between banker and client that had encouraged relational reputation formation and, at the same time, they massively expanded their financial scale.

The problems that gave rise to the cultural mores of relational investment banking did not affect the technocratic banker. We have already noted that technocrats can codify their rules and, hence, do not need to maintain a reputation for making judgments in situations of conflict. Indeed, they appear sometimes affirmatively to disavow any responsibility for judgment. This occurred during the Congressional hearings in the wake of the ABACUS transaction. ${ }^{13} \mathrm{ABACUS}$ was a synthetic unfunded collateralized debt obligation created by Goldman Sachs in response to a demand from a hedge fund client who wanted to assume a very specific risk in the market for residential mortgages. Goldman was accused of failing to explain to the buyers of the ABACUS notes, who collectively lost over $\$ 1$ billion on the trade, that the hedge fund client participated in the selection of the underlying mortgages. Goldman eventually made a \$550 million payment to the SEC to settle the case. In his testimony to the U.S. Congress, Lloyd Blankfein, then Goldman's CEO, stated of transactions like ABACUS that:

"In the context of market making, that is not a conflict. What clients are buying ... is ... an exposure. The thing that we are selling to them is supposed to give them the risk they want. They are not coming to us to represent what our views are.... They shouldn't care."

In this comment, Mr. Blankfein exhibits an entirely technocratic outlook. His remarks dismiss conflicts over ABACUS as completely irrelevant. By his account, clients are buying a carefully packaged and clearly defined risk from Goldman Sachs, and they should not expect the bank to exercise any judgment on their behalf. This perspective is entirely consistent with Mr. Blankfein's statement, in another context, that "we are a technology company." ${ }^{14}$ In a purely

\footnotetext{
13 For details see S. Davidoff, A.D. Morrison, and W.J. Wilhelm, Jr., "The SEC v. Goldman Sachs: Reputation, Trust, and Fiduciary Duties in Investment Banking," Journal of Corporation Law, 2012.

14 For example, see "Goldman Sachs is a Tech Company," Business Insider, April 12, 2015. The same article reported that about 9,000 of Goldman's 33,000 full-time employees were engineers and programmers.
}

technocratic business, it would be appropriate to downplay the importance of conflict and the role of judgment; we argue below that Mr. Blankfein's statement captures only part of the truth about even the most technocratic of modern investment banks.

Mr. Blankfein's statements do more than capture a truth about technocratic banking. They also exhibit a cultural perspective at variance with the one that rules the relational bank. Technocratic bankers win clients, earn profits, and achieve promotion by being smarter than their peers, but not necessarily by exercising good judgment on behalf of their clients. That is, in place of the informal character and relational reputations that are valued by the relational banker, technocratic bankers need to demonstrate cleverness. Precisely because they can write down what they are doing, technocratic bankers do not directly rely in their businesses upon the corporate reputation of their employer.

In short, technocratic bankers celebrate the ability to structure complex deals that can be contracted upon and sold in large volumes. That ability is not reliant upon an individual or institutional reputation for exercising judgment fairly and, hence, those abilities are downplayed in technocratic banking cultures. The foundation of technocratic success, and the basis for cultural approval in technocratic banks, is individual skill. In short, technocratic banking breeds star cultures. ${ }^{15}$ The technocratic banker becomes a star by building an individual technocratic reputation for clever structuring.

A technocratic reputation need not be consistent with a character reputation, and the two may even be inconsistent. To see why, consider an investment banker who has the opportunity to learn more about a technocratic marketplace by experimenting on her customers. Doing so is not in the customer's best interests and so will likely undermine the banker's character reputation. But it may build the banker's technocratic human capital and, in the long run, may enable her to earn higher profits when she sells her new skills. We might like to imagine that the banker faces a conflict between the interests of her clients and her desire to build technocratic skill but, from the perspective of the banker, this is no conflict at all; she will opt to build technocratic skill at the expense of her clients. As a result, we claim that technocratic bankers may innovate more than is socially desirable, and that they may push their clients into second-best trades so as to build, and then to exhibit, technocratic skills. ${ }^{16}$

15 For a model of the tension between individual and organizational reputation concerns in this setting, see Z. Chen, A.D. Morrison, and W.J. Wilhelm, Jr., "Investment Bank Reputation and "Star" Cultures," Review of Corporate Finance Studies, 2015.

16 For a detailed development of this argument, see Z. Chen, A.D. Morrison, and W.J. Wilhelm, Jr., "Traders vs. Relationship Managers: Reputational Conflicts in Full- 
Technocratic banking is an individual skill and, hence, it is transferrable to any institution with sufficient capital and computational power to support it. It is perhaps unsurprising that the move towards technocratic banking of the last five decades has been accompanied by a steady increase in investment banker labor mobility. Over the same period, relational banking, measured by the degree of exclusivity in client's banking relationships, suffered a sharp decline. ${ }^{17}$

We claimed in our discussion of Lloyd Blankfein's remarks about conflicts that his apparent focus on the technocratic elements of his bank was inappropriate, even in the context of an entirely contractual business like $\mathrm{CDO}$ structuring and sales. We now attempt to substantiate this point.

\section{Braiding Technocratic and Relational Products}

Relational bankers and technocratic bankers frequently attempt to solve similar problems, but they do so in very different ways. Nevertheless, recent years have seen M\&A bankers, for example, effectively combine relational and technocratic skills in the service of their clients in ways that are complementary and essential to the transaction's success. We refer to such products and services as braided, and we will refer to a bank as braided if the ability to offer braided products and services is a critical part of its business model. We contend that every successful full-service investment bank is braided.

General Mills' 2000 acquisition of Pillsbury from Diageo provides a useful illustration of the ways in which technocratic skills can complement relational bankers' informal strategies. Spinning out Pillsbury was a central element of a major restructuring effort undertaken by Diageo, and General Mills was a natural "strategic" buyer. However, negotiations had reached an impasse: Diageo demanded $\$ 10.5$ billion for Pillsbury, while General Mills stood firm at its offer of $\$ 10$ billion. About $\$ 5$ billion would come from General Mills' assumption of Pillsbury's debt obligations; the remainder of the consideration would be General Mills shares. Diageo's demand nominally valued the shares at a premium to their market price. ${ }^{18}$ In essence, the $\$ 500$ million gap between Diageo's offer price and General Mill's bid reflected General Mills' belief that, even at the implied premium offered by Diageo, their shares were undervalued. General Mills may have had good reason for this belief but Diageo could not

Service Investment Banks," Review of Financial Studies, 2017.

17 See A.D. Morrison, C. Schenone, A. Thegeya, and W.J. Wilhelm, Jr., "Investment Banking Relationships: 1933-2007," Review of Corporate Finance Studies, 2018.

18 On July 14, 2000, General Mills and Diageo announced an agreement valuing the transaction at $\$ 10.5 \mathrm{bn}$ by placing a $\$ 38$ per share valuation on 141 million General Mills shares. Trading on General Mills on the New York Stock Exchange closed at $\$ 36.31$. verify the claim and neither party wished to be perceived by its board as having given in to the other.

The stalemate was broken when a General Mills banker proposed that they agree to Diageo's $\$ 10.5$ billion valuation but bridge the $\$ 500$ million gap with a contingent value right (CVR). The CVR combined a long call option on General Mills shares struck at Diageo's nominal valuation of $\$ 38$ with a short call option struck at $\$ 42.55$. The CVR was sized to provide General Mills with a minimal payoff if its share price did not rise above Diageo's valuation after one year. Alternatively, if its share price finished above Diageo's valuation, Diageo would make a payment to General Mills that increased linearly with the share price up to a maximum of $\$ 642$ million.

The present value of the CVR using the Black-Scholes model was roughly $\$ 250$ million. In other words, the counterparties split the difference between their expected valuations. Had General Mills been able credibly to convey any private information that was not priced into its shares then, in principle, the parties could have split the difference without the CVR; the CVR added value because it enabled General Mills more credibly to stand behind its beliefs. Moreover, the CVR was designed in such a way that its present value was relatively insensitive to a fairly wide range of beliefs regarding the share price volatility. General Mills' CFO commented that "We genuinely believe this is a way in which they could have their cake and we could eat it too. There's no question... that absent this instrument we wouldn't have been able to reach this deal." 19

Braided banks often offer to finance the acquisition of firms for which their advisory divisions are seeking buyers. Such offers of "stapled finance" create an intimate connection between the technocratic practice of leveraged lending with the relational discipline of sell-side M\&A advice. But, in contrast to the previous example, stapled finance represents both an opportunity and a threat for both the relational banker and her client. On the one hand, guaranteeing financing places bidders on more nearly equal footing with one another and thus may produce a more competitive bidding process $^{20}$ and so reduce risk in closing the deal. As a consequence, the relational banker may be better able to exhibit the virtues that build her own character reputation and that support her bank's relational reputation. On the other hand,

19 See S. Lipin, "Firms Roll Out a Tool To Save Doughboy Deal," Wall Street Journal, $7 / 21 / 00$. Ironically, a banker from Evercore, a boutique advisory firm, proposed the CVR. In this case, the boutique firm was able to deliver the braided service because the CVR, the technocratic component of the deal, did not require a capital commitment. It was simply a contractual agreement between the counterparties, the value of which could be credibly established within the Black-Scholes framework.

20 See P. Povel and R. Singh, "Stapled Finance," Journal of Finance, June 2010. 
if her technocratic colleagues pressure her to favor a bidder who is more likely to accept their financing offer, then she will harm the reputational assets upon which her long-run prosperity rests. The problem is exacerbated by the fact that financing fees can easily exceed advisory fees. The ability to manage this type of conflict distinguishes the bank that uses its technocratic ability to provide stapled finance appropriately from the bank that does not.

A series of recent opinions issued by the Delaware Chancery Court have called into question the ability of bankers and the boards they advise to manage this conflict appropriately. ${ }^{21}$ For example, while serving as a sell-side advisor to Del Monte in 2010, Barclays steered the deal toward KKR, with which it had a strong relationship, in part because it believed KKR was more likely to accept its financing offer. Shareholders claimed that the seller's board failed in its fiduciary duty to pursue the best deal available. This conflict is very hard to police; it would have been challenging, if not impossible for Del Monte's board to monitor Barclays' every action. However, on February 14, 2011, Vice Chancellor Laster noted in response to a shareholder request for postponement of the vote on the sale of the firm, "Although the blame for what took place appears... to lie with Barclays, the buck stops with the Board."22 Shortly after this statement, RBC was similarly implicated in its role as an advisor to Rural Metro when it was sold to Warburg Pincus. On March 7, 2014, Laster found RBC liable for aiding and abetting Rural Metro's board in a breach of its fiduciary duty and later upheld a $\$ 76$ million judgment for damages against RBC. This was the first time the Delaware Chancery Court held an investment bank liable to shareholders for a corporate board's actions.

In summary, braiding technocratic skills with the skills of relational bankers can improve outcomes for bank clients. However, a failure to manage the incentive and cultural conflicts between technocratic and relational bankers can be damaging to both their clients and their bank. The situation is complicated by the fact that, precisely because relational and technocratic modes of business are braided in modern banking deals, those deals are increasingly susceptible to legal assess-

21 See "In re Toys "R" Us, Inc. Shareholder Litigation," (Del. Ch. 2005), "In Re Del Monte Foods Company Shareholders Litigation," (Del. Ch. 2011), and "In Re Rural Metro Corporation Stockholders Litigation" (Del. Ch. 2014). For discussion of the cases and their implications, see W. W. Bratton and M.L. Wachter, "Bankers and Chancellors," Texas Law Review, 2014, and A.D. Morrison and W.J. Wilhelm, Jr., "Trust, Reputation, and Law: The Evolution of Commitment in Investment Banking," Journal of Legal Analysis, 2015.

22 "In Re Del Monte Foods Company Shareholders Litigation," (Del. Ch. 2011). In the event, KKR, teaming with Vestar and Centerview, acquired Del Monte and shareholders filed a complaint against the board. Barclays contributed about $\$ 45 \mathrm{~m}$ to the settle the complaint including forfeiting its $\$ 21.5 \mathrm{~m}$ fee. ment. As banks rely increasingly upon technocratic solutions, it becomes easier for courts to attribute legal responsibilities to them and, in so doing, they may accelerate the movement away from relational banking and towards technocratic banking. The Delaware Chancery Court judgments discussed above, with their insistence upon the Board's responsibility for managing conflicts itself using formal contractual devices, appear to support this conclusion. ${ }^{23}$

The Delaware Chancery Court imposed judgments totaling more than $\$ 110$ million against Barclays and RBC, but the reputational damage suffered by both banks and the boards that hired them was arguably at least as significant as the pecuniary penalties. Clearly, banks and their clients are still learning how best to govern braided bank relationships. In the next section, we consider the problems that they face.

\section{Governing the Braided Bank}

Our discussion so far highlights the emergence of a new way of doing banking business. That approach has emerged as the extra-legal and trust-based relational approach of the traditional banker has been supplemented by the arm's-length contractual techniques of the new technocratic banker. Banks have not jettisoned one approach in favor of the other; nor have they divided their activities into those that are purely relational and those that are entirely technocratic. Instead, in almost all of their activities, bankers have braided the two approaches. This approach enables efficiency gains and creates new modes of doing business. But it also raises difficult governance challenges. As we have already noted, bankers who learned their craft on the relational side of the business have different cultural norms and expectations than their colleagues on the technocratic side. Behavior that seems entirely rational in one cultural context may appear irrelevant or misguided in another. And, as technocratic ways of transacting become increasingly integrated into relational businesses, codified legal solutions to governance problems become available for the first time and, as we noted at the end of the previous section, they may also become compulsory. Bankers are still learning how to address these problems. We now try to shed some light upon their efforts by examining in turn some important braided banking businesses.

\section{M\&A Advisory Work}

One approach to the problems we have identified is to attempt to separate relational from technocratic banking. In the M\&A

23 See Alan D. Morrison and Wilhem J. Wilhelm, Jr. "Trust, Reputation, and Law: The Evolution of Commitment in Investment Banking." Journal of Legal Analysis, Winter 2015, pp. $411-412$ 
advisory world, boutique firms largely achieve this separation and, because they deliberately exclude businesses within which technocratic cultural values dominate, they avoid the conflict management problems that a technocratic culture appears to create. Some boutiques go further in their efforts to avoid even a perception of conflict by focusing on sell-side advising or restricting their advisory relationships to a single or narrow set of clients in a given industry.

At their inception, most if not all of the boutique firm founders emphasized their belief that a return to the culture and organizational structure of the early investment banking partnerships was necessary if their business was to succeed. ${ }^{24}$ In a 2004 article in the American Economic Review, we show how private partnerships can provide powerful incentives for partners and junior employees who wish to become partners to cooperate in the development and preservation of what we referred to earlier as an individual's character reputation and the firm's relational reputation. ${ }^{25}$ An important element of the organizational structure is that retiring partners must sell their stakes to rising partners who wish to enter the partnership only if they have been groomed to internalize the character traits required to preserve the firm's relational reputation. Thus the partnership structure embodies a governance mechanism that is particularly supportive of relational banking. But, in a related article, we also show that this governance mechanism can be sustained only at limited scale. It is ironic then that some of the most prominent advisory boutiques have grown to the point where the partners decided to go public. ${ }^{26}$

Despite the apparent advantage that boutique banks have in relational banking, full-service banks continue to dominate the M\&A advisory landscape. The most prominent banks offer technocratic as well as relational services. These services are not simply offered in different divisions of a large bank that hopes thereby to attract customers who want a one-stop shopping experience; the services are often intimately connected. Moreover, relational services can be complemented by information gleaned from the large volume and variety of the typical full-service bank's deal flow. A natural question is how the benefits derived from this type

24 Joseph Parella, Peter Weinberg, and Terry Meguid provide a detailed account of their thought process at the founding and early years of Parella Weinberg Partners to Harvard case writers Clayton Rose and Aman Malik. See "Parella Weinberg Partners: New Firm, Old Values," Case Number 9-312-013, Harvard Business School Press, September 29, 2011.

25 See "Partnership Firms, Reputation, and Human Capital," American Economic Review, December 2004.

26 For example, Greenhill (2004), Evercore (2006), and Moelis (2014). As we write, Parella Weinberg Partners is actively planning a public offering. See Lucinda Shen, "Parella Weinberg's Asset Management Business Spins Off Ahead on IPO," Fortune, March 8, 2019. of braiding can be sustained, given the cultural conflicts between technocratic and relational bankers.

One possibility would be to rely upon the courts. For example, one could simply prohibit the provision of stapled finance by M\&A advisors, or, more generally, one could attempt to prohibit all forms of conflict among those advisors. Alternatively, one could guarantee that firms would be immune from legal action if they were to engage a second, unconflicted boutique bank in addition to their braided bank. Some recent legal scholarship concludes that the benefits of either type of intervention would be limited, and that judicial scrutiny would provide a more effective form of governance. ${ }^{27}$ This conclusion is interesting because it suggests that one cannot resolve braided governance problems with codified solutions - that, in other words, braided banking is still tacit and judgment-based at a very deep level. But, in assigning the right to exercise judgment to the courts, it also concludes that braiding has undermined the ability of bankers and their clients to create and police their own governance devices. In practice, of course, many target boards operating in the shadow of court intervention have elected to incur the costs of engaging a boutique advisor to work alongside their braided M\&A banker. In other words, even in the absence of a formal requirement that they pay for this type of advice, target firms opt to behave as if such a requirement exists. In short, braiding has made it inevitable that courts become engaged in the governance of banking relationships, and that that engagement has sometimes led to defensive behavior that none of the parties to the governance relationship would likely have chosen otherwise.

\section{Securities Issuance}

There appears to be a similar tendency among issuers of new securities, especially IPOs, to supplement the services of fullservice banks with independent advice from independent corporate finance advisors. These advisors include boutiques such as Lazard and Rothschild that also provide M\&A advice as well as more specialized firms, such as STJ Advisors. A recent study of 220 London-based IPOs from 2010 through 2015 reports that almost a third (32\%) of the issuers in those deals hired a corporate finance advisor. ${ }^{28}$ Besides helping the issuer choose its lead bank(s) and syndicate members and advising it on share pricing and allocation, the advisor monitors the ways in which the issuer's interests are balanced against those of the banks' buy-side clients. Although this

27 See William W. Bratton and Michael Wachter, "Bankers and Chancellors." Texas Law Review, 2014.

28 T. Jenkinson, H. Jones, and F. Suntheim, "Quid Pro Quo? What Factors Influence IPO Allocations to Investors?," Journal of Finance, October 2018. 
study considers equity markets, independent advisory firms also appear to be gaining traction in debt markets where advances in financial engineering have provided technocratic bankers with strong incentives to promote complex hybrid securities in pursuit of higher fees and opportunities to showcase their technical capabilities, even when their clients would be better-served by a simple product. ${ }^{29}$

In effect, securities issuers that hire corporate finance advisors to monitor their bankers are moving in the direction of separating advice, or relational services, from transaction execution, which is more nearly a technocratic function. To be sure, it is hard to imagine advice ever becoming fully separate from transaction execution in the M\&A business. However, there is a clear and present end point to this movement in securities issuance: electronic securities auction platforms, such as that maintained by WR Hambrecht since 1999, provide, in principle, ${ }^{30}$ a purely technocratic solution to share pricing and allocation that eliminates the potential for violations of trust such as those that we described in the introduction. Moreover, it is well understood that a well-designed auction mechanism can be a very close approximation to the incentive structure for information exchange that we ascribed to the relational banker's role in IPOs. Each is simply a mechanism for pricing and allocating shares. The only difference is that auctions are (or should be) governed by explicit rules, whereas the book-building process carried out by relational bankers permits exercise of human judgment within the boundaries of informal rules.

The continued preference for book-built IPOs strongly suggests that human judgment remains sufficiently special for issuers still to pay higher fees to access it, and for them to run the risk that their trust is violated by their relational banker. We have rehearsed this argument in several earlier articles in this journal and our suggestions that the time for electronic auctions was ripe were proved wrong. ${ }^{31}$ That said, the confluence of corporate finance advisors, deepening markets for private equity, and recent experiments such as Spotify's direct offering (or non-IPO ${ }^{32}$ ) suggest to us that the traditional methods that have proven so lucrative to braided banks face

29 M. Farrell and L. Hoffman, "Upstarts Crash Wall Street's \$7 Billion Capital-Markets Party," Wall Street Journal, June 25, 2018.

30 We qualify this statement because issuers may elect to not follow the explicit auction rules for pricing and allocating shares. Google's 2004 IPO, executed on the Hambrecht platform, is the most prominent example of a so-called "dirty auction." We contend that holding out the option to not follow the auction rules substantially undermines the benefits of this approach.

31 Most recently, see Z. Chen, A. D. Morrison and W. J. Wilhelm, Jr., "Another Look at Bookbuilding, Auctions, and the Future of the IPO Process," Journal of Applied Corporate Finance, Vol. 26, No. 2, (Spring 2014).

32 See Matt Levine, "Spotify's Non-IPO Really is Novel," Bloomberg Opinion, January 4, 2018 unprecedented pressure, in no small part as a consequence of governance failures within braided banks.

\section{Over-the Counter Derivatives and Structured Products}

Banks both originate complex over-the-counter financial products and also stand as a counterparty or a market-maker for the resulting securities. As in the ABACUS case that we discuss above, banks in these markets may view themselves as arm's-length transactors whose responsibilities to their clients are limited by the explicit terms of their contracts. In contrast, a client that is used to dealing with the same institution in a more relational braided context may view its bank as extending a variety of tacit and relational guarantees regarding the nature and suitability of the products it trades. The simplest way to address this problem may be to adopt technocratic legal approaches that make the precise nature of the relationship as explicit as possible.

The legalistic approach is enabled by a variety of contractual innovations that were spurred by the emergence of the derivatives markets. The first, to which we have already referred, is the ISDA Master Agreement, which was developed as a standard set of terms to govern trades in swaps and other derivative securities. The Agreement is notable for two reasons. First, and most obviously, it explicitly lays out the obligations of both parties to standard derivative contracts; and in so doing, it identifies the circumstances under which the contract can be treated as breached, and also the remedies that each party has in case of breach. Second, and more pertinently from the perspective of this article, the Agreement was reached through a process of negotiation and discussion among significant derivatives traders. That negotiation both surfaced important questions, and also generated a wide understanding that the Agreement constituted the whole of the relationship between derivative traders. That is, the Agreement rests upon a general relational understanding of its scope and its limitations. Signatories to the Agreement therefore accept that understanding.

The ISDA Master Agreement is a piece of private law. That is, it was negotiated by private actors who, while they rely upon the courts for enforcement, determine its content without reference to state actors. Court intervention in the terms of the Agreement may sometimes be justified by socioeconomic considerations, but it also serves to muddy the waters, because it undermines the relational understanding of the extent of the Agreement and the nature of the relationships that it creates. For example, if a court might at any time rule that one party to the Agreement was entitled to advice not laid out in the Agreement, then the social context and the cultural implications of the Agreement would become unclear 
and, hence, the Agreement would arguably be a less effective means of governing braided bank relationships.

Some evidence in support of this position is provided by the growing use of formal non-reliance provisions, in which one party to a deal explicitly acknowledges that it understands that the other may have private, price-relevant, information. Those clauses are inserted into "Big Boy Letters," which attempt to prevent the type of ex post court interpretation of relationships that, we have argued, may undermine the purpose of the Master Agreement. Big Boy letters and other forms of non-reliance provisions are now standard in most securities trades not transacted on a public exchange and in almost all claims trades. ${ }^{33}$

The Big Boy letter is one way to insulate relationshiporiented legal innovation from state intervention. Another is the creative use of Special Purpose Entities (SPEs). If a bank and its client each trade through a separate entity that could not conceivably be interpreted as providing advice or sustaining a fiduciary liability, then they may be able to insulate themselves from the court's attempt to impose a fiduciary standard upon their dealings. This is one way to understand the ubiquity of SPEs in the derivatives markets. For example, the ABACUS deal discussed above was structured through an SPE that was entirely contractual and, hence, arguably without fiduciary responsibilities. ${ }^{34}$ Of course, as things turned out, the SEC reached through the ABACUS SPE and ascribed responsibilities to Goldman. Goldman drew investor's attention to its potential conflicts in the ABACUS prospectus and it considered drafting a Big Boy letter to emphasize its arm's-length view of the relationships it created through the ABACUS deal. Goldman may well have avoided a great deal of reputational and financial damage had it gone ahead and drafted the letter. ${ }^{35}$

33 See Daniel Sullivan, "Big Boys and Chinese Walls," University of Chicago Law Review, Winter 2008, p. 560.

34 For a discussion of this point, see William W. Bratton and Adam J. Levitin, "A Transactional Genealogy of Scandal: From Michael Milken to Enron to Goldman Sachs." Southern California Law Review, 2013. Bratton and Levitin characterize the ABACUS SPE as a "gapless contractual firm" and conclude that "the deal, viewed as a whole, looks less like a long-term investment of capital than a collection of arm's-length one-off bets entered into at the swaps desk - a series of discrete contractual trades without fiduciary overtones." (Id. p. 858). Relatedly, when Goldman Sachs structured its ill-fated relationship with the Libyan Investment Authority (LIA), it required that any loans to the LIA be granted through an SPE, because of concerns about repayment in the event that the LIA experienced losses on trades funded by the loans. In the event, Goldman and the LIA entered into derivative contracts containing the leverage sought by the LIA but for which Goldman was compensated in advance. See para 298 of the High Court's judgment in Libyan Investment Authority v Goldman Sachs, October 2016.

35 See Alan D. Morrison and William J. Wilhelm, Jr. "Trust, Reputation, and Law: The Evolution of Commitment in Investment Banking." Journal of Legal Analysis, Winter 2015, note 106.

\section{Internal Governance}

Braided banks combine relational and technocratic modes of business. It seems reasonable to imagine that such a bank might have to supplement traditional cultural and tacit governance devices with formal, codified devices. An interesting example of this approach has recently been provided by Goldman Sachs, which embarked on a careful examination of its business practices and cultural mores in the wake of the ABACUS hearings. The resulting Report of the Business Standards Committee is a 67-page attempt to codify Goldman's values and ways of doing business. ${ }^{36}$

The Report is a sophisticated document whose authors were clearly cognizant of many of the problems that we discuss above. For example, David Greenwald, deputy general counsel at Goldman Sachs, states that the bank was aware that it was experiencing a shift towards a legalistic culture, but aimed to shift the firm's perspective to emphasize the values that underpinned its relational activities:

"There's a tension between driving revenue and ensuring were only earning revenue from those things we should. It's not legal versus illegal... It can be boiled down to four words: Can we? Should we?.. We've always focused on the 'can we' question... Now we're focused on 'should we.' '37

The attempt by Goldman and other banks to codify the formerly tacit elements of their relational culture is an interesting development. It is too early to say whether or not this approach will succeed. As a recognition of the cultural dissonance at the heart of the braided bank, it is an important step forward. But the relational culture was forged in a largely extra-legal environment and it relied upon the long-term incentives provided by a relational reputation. It may prove hard in practice to sustain that culture in a different, increasingly legalistic environment.

\section{Conclusion}

This article examines the problems that modern investment banks experience as they manage the conflicts of interest to which they are exposed. The traditional investment bank relied upon its relationships and so depended on its reputation for behaving appropriately in complex situations that are not susceptible to contracting. That type of bank was valuable because it could sustain trade between counterparties who could not rely upon formal legal devices to manage

\footnotetext{
36 Goldman Sachs, Report of the Business Standards Committee, January 2011.

37 Rajiv Lal and Lisa Mazzanti, "Goldman Sachs: Anchoring Standards after the Financial Crisis," Harvard Business School Case 9-514-020, May 2014, p. 12.
} 
their conflicts. As a result, investment banks were inevitably conflicted: indeed, they were designed to absorb and to manage conflicts of interest in financial markets.

The recent emergence of the technocratic banker has exposed the old model of banking to new stresses. Technocratic bankers specialize in finding contractual solutions to banking problems - that is, a purely technocratic solution that resolves every conceivable conflict by embedding it in a contractual term. As a result, the properties that make for a successful and respected technocratic banker differ from those exhibited by a successful relational banker. The technocratic banker cannot be expected to manage conflicts in the same way the relational banker does.

Cultural incompatibilities are a problem in the modern bank because, in almost all of its businesses, it closely combines technocratic and relational approaches into what we have characterized as a braided business model. That model is replete with possibilities; but because it combines two very different cultures, it also presents serious governance challenges. Banks are still learning how best to address those challenges. In some businesses they have spun off relational activities to boutiques where they will be largely untainted by technocratic concerns; in others they have leaned more upon the courts. Some businesses rely upon specialist advisors, and some use private legal solutions, such as the ISDA Master Agreement, to delineate their relationships.

Each of the above approaches has proved — and is likely to prove-only partly successful. Cultural standards that evolved in a business that is little-susceptible to formal contract are unlikely to survive unchanged when legal and technological advances allow both bankers and legislators to rely upon codified rules. Hence, while recent attempts by investment bankers to codify their cultural standards are a laudable attempt to retain the best elements of their relational business in the braided world, we suspect that they are only a staging post on the road to a new understanding of the roles and behaviors of the investment banker. Precisely what that new understanding entails is a topic of ongoing investigation. 